\title{
66. PRELIMINARY PALEOMAGNETIC RESULTS OF LAMINATED SEDIMENTS FROM DEEP SEA DRILLING PROJECT HYDRAULIC PISTON CORE SITE 480, GUAYMAS BASIN, GULF OF CALIFORNIA ${ }^{1}$
}

\author{
Robert Karlin and Shaul Levi, School of Oceanography, Oregon State University, Corvallis, Oregon
}

\section{INTRODUCTION}

The sediments of Deep Sea Drilling Project (DSDP) Hole 480 in the Guaymas Basin, Gulf of California $\left(27^{\circ} 54.10^{\prime} \mathrm{N}, 111^{\circ} 39.34^{\prime} \mathrm{W}, 665 \mathrm{~m}\right.$ water depth), consist of 152 meters of finely laminated diatomaceous ooze interstratified with mottled and homogeneous muds. At Site 480 , the Serocki-Storms-Cameron hydraulic piston corer was used for the first time and obtained $80 \%$ of a virtually undisturbed sedimentary section (Curray et al., 1979). Because of a high sedimentation rate and an anaerobic, low-energy depositional environment underlying a seasonal upwelling regime (Schrader et al., 1980), the sediments of Site 480 offer an excellent opportunity to study the behavior of the geomagnetic field over the past few $10^{5}$ years.

In this chapter we present preliminary results of natural remanent magnetization (NRM) measurements of samples of varied lithology taken throughout the sedimentary section. In this first phase of our work, we examine the reliability of the magnetic recording in the different types of sediments and make a preliminary assessment of whether any significant paleomagnetic excursions were recorded at Site 480 .

\section{METHODS}

We took 286 samples at approximately 40 -cm intervals from undisturbed sections of Cores 1 through 31. A thin-walled, square stainless steel tube, mounted in a frame and aligned perpendicularly to the core liner, was used to obtain undisturbed samples $\left(v=6.5 \mathrm{~cm}^{3}\right)$. Where laminated sediments were slightly tilted $\left(<5^{\circ}\right)$ relative to the core liner, we aligned the samples parallel to the laminations.

Reconnaissance measurements of NRM were made on 20 samples using a Schoenstedt DSM-1 spinner magnetometer. Because NRM intensities were extremely weak, we made all subsequent measurements, including those on the pilot samples, on a three-axis SCT cryogenic magnetometer. For each remanence determination, three-axis measurements were made on the cryogenic magnetometer in six different orientations. Regarding each orientation as an independent observation, we calculated mean directions, intensities, and measures of angular dispersion. The angular dispersion values were used as estimates of the internal consistency and homogeneity of the magnetization for each sample.

To date, we have measured NRM on all of the samples, and 73 samples from Cores 25 through 31 and 15 other pilot samples have undergone stepwise partial alternating field (AF) demagnetization to at least $100 \mathrm{Oe}$ or to the limit of reliable measurement. Based on relative changes in direction at the 50-, 75-, and 100-Oe levels, we considered that a cleaning field of 75 Oe was optimum for obtaining stable directions.

Of the 286 samples, we excluded 22 because of probable coring or sampling disturbance. The directions of an additional seven samples

\footnotetext{
${ }^{1}$ Curray, J. R., Moore, D. G., Init. Repts. DSDP, 64: Washington (U.S. Govt. Printing office).
}

were unreliable because of weak magnetization and lack of internal consistency.

For the top three cores, varve counts of 29 samples (provided by A. Soutar and R. Burn [personal communication, 1980]) were used to estimate temporal sampling resolution in the laminated sections of the upper part of the sedimentary column. Considering each laminae pair as a single annual varve, the varve counts yielded an average sedimentation rate of $103 \pm 13 \mathrm{~cm} / \mathrm{ky}$. and a time span of $20 \pm 3$ years per paleomagnetic sample.

\section{RESULTS AND DISCUSSION}

\section{NRM Directions}

Natural remanent magnetization inclinations, wetweight normalized intensities in emu/gm, and their respective standard deviations are summarized by core in Figures 1 and 2. We observed no significant intervals of reversed polarity in the sediments, although several samples in Cores 18, 20, and 22 showed inclinations of less than $30^{\circ}$. But further magnetic "cleaning" and additional sampling are required before we can ascertain the significance of these zones of shallow inclination.

For the entire section, the mean NRM inclination for 257 samples was $46.4 \pm 14.3^{\circ}$, or $45.2 \pm 6.4^{\circ}$ if averaged by core. These values are remarkably close to the geocentric axial dipole inclination of $46.6^{\circ}$ expected at the latitude of this site. Thus, when averaged over the greater-than $10^{5}$ years represented by the sedimentary section from Hole 480, no inclination error such as found in some dry and wet lake sediments was observed (Denham and Cox, 1971; Verosub, 1977). In addition, no shallowing of the inclination with depth, presumably caused by compaction (Creer, 1974), was apparent in the sediments.

The AF demagnetizations indicate that the similarity between the site mean NRM and geocentric axial dipole inclinations was probably not due to modern viscous overprinting. Upon demagnetization, the 73 samples from Cores 25 through 31 , as well as the 15 pilot samples from other cores, had, in general, median destructive fields (MDFs) of 75 to $150 \mathrm{Oe}$ and showed vector changes in direction of less than $15^{\circ}$ between the NRM and 50-, 75- and 100-Oe levels (Fig. 3). For the 75-Oe level, the core mean inclinations for Cores 25 through 31 average $45.2 \pm 5.3^{\circ}$. This value is similar to the corresponding NRM core mean average of $46.9 \pm 5.5^{\circ}$ for the same cores, thus suggesting that the NRM core means are relatively uncontaminated by secondary magnetization.

To gain some insight into the reliability of the magnetic recording among the various lithologies, we grouped the 257 samples into laminated, homogeneous, mottled, 


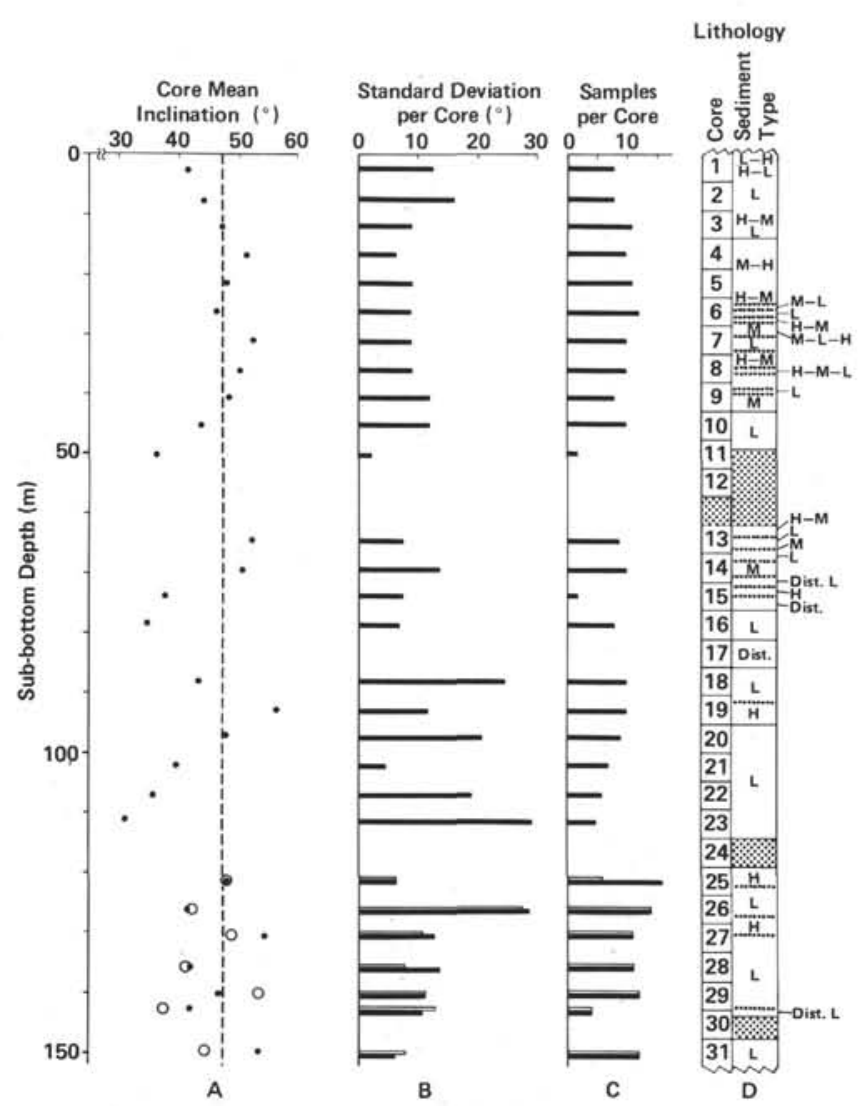

Figure 1. Summary of NRM core mean inclinations (A), standard deviations per core (B), number of samples per core (C), and gross lithology of Cores 1-31 (D). The dashed line in (A) at $46.6^{\circ}$ is the geocentric axial dipole inclination expected at the site. Open circles in (A) and open bars in (B) and (C) refer to samples AF demagnetized at $75 \mathrm{Oe}$. In the lithologic column of (D), L = laminated, $\mathrm{H}=$ homogeneous, $\mathrm{M}=$ mottled, and Dist. = disturbed sediments. Stippled areas in (D) are unrecovered sections.

and other (layered, mottled layered, and the like) sediment classes. Homogeneous and mottled sediments were distinguished by the presence or absence of color changes or sedimentary structures such as burrows on the $\mathrm{X}$-radiographs.

The laminated, homogeneous, and mottled sediments have mean inclinations very close to the expected geocentric axial dipole value (Table 1; Fig. 4). The larger standard deviation in the inclinations of the laminated sediments probably reflects the greater number of samples in this class, since the standard error $(s / \sqrt{N})$ of the various sediment classes is comparable.

The homogeneous and mottled sediments have virtually identical mean inclinations and similar standard deviations of less than $10^{\circ}$ (Table 1). Assuming that the NRM predominantly reflects the behavior of the primary remanence, the similarity of the mean inclinations of the homogeneous and mottled sediments to the dipole value and the relatively small scatter among the samples suggest that the remanence was locked-in at a depth below the level of benthic activity. Thus, postdepositional bioturbation probably has not affected the remanence.
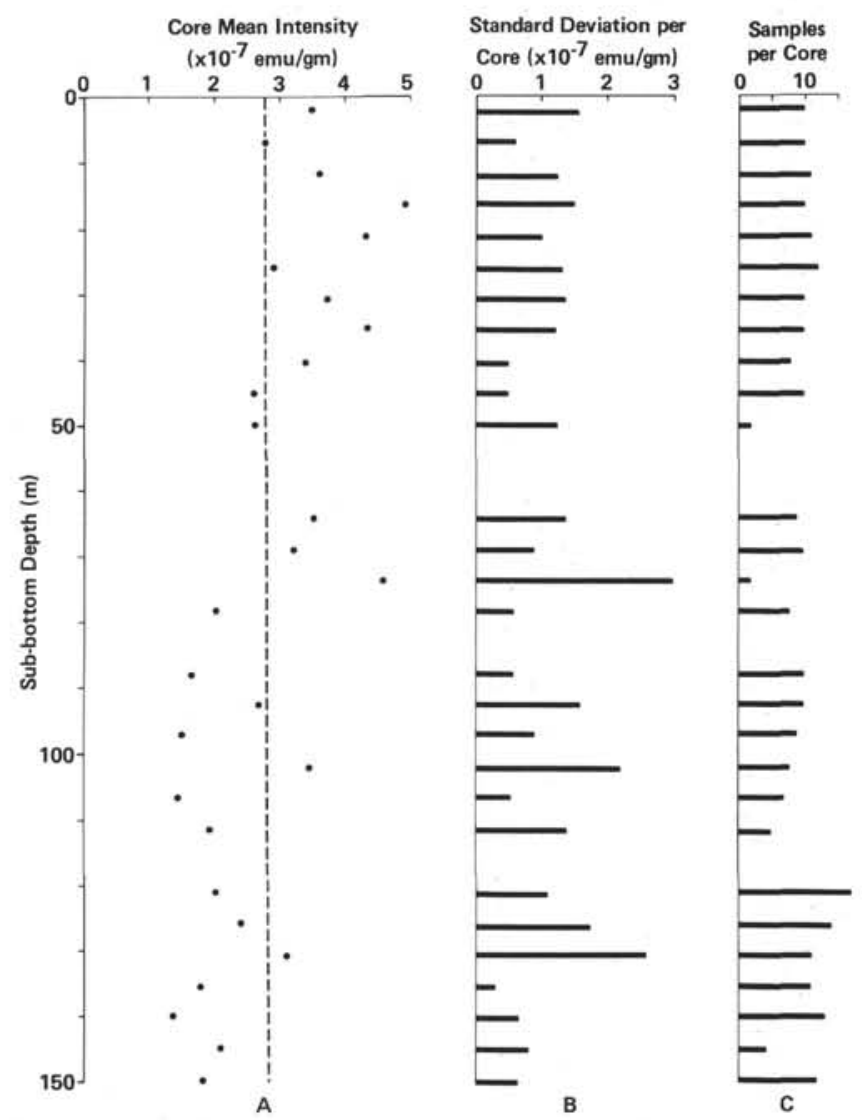

Figure 2. NRM core mean intensity variations $\left(\times 10^{-7} \mathrm{emu} / \mathrm{gm}\right.$ wet weight) with depth (A), standard deviations per core (B), number of samples per core for Cores 1-31 (C). In (A), the dashed line is the NRM Site mean intensity.

\section{NRM Intensities}

For the entire section, the NRM intensities for all samples averaged $2.8 \times 10^{-7} \mathrm{emu} / \mathrm{gm}$ wet weight. Above 75 meters, the NRM mean intensities are higher, by a factor of 1.7 , than the mean intensities below this depth (Fig. 2; Table 2). In Figure 5, the frequency distribution of intensity for the different lithologies shows that the laminated sediments have substantially lower intensities than the other lithologies-probably because of a higher percentage of diluent biogenic material in the laminae. Since most of the homogeneous and mottled sequences occur above 75 meters, some of the observed intensity difference may be attributable to differences in lithology; however when the lithologies are considered separately (as in Table 2), in the upper 75 meters the individual lithologies show intensities higher, by factors of 1.4 to 1.5 , than their counterparts in the lower half of the section. Nevertheless, within each lithology, NRM mean inclinations above and below 75 meters are identical. Although only limited bulk density and GRAPE data are available, increased compaction below 75 meters may have caused randomization of a portion of the magnetic carriers and a reduction in NRM intensity with no accompanying decrease in in- 


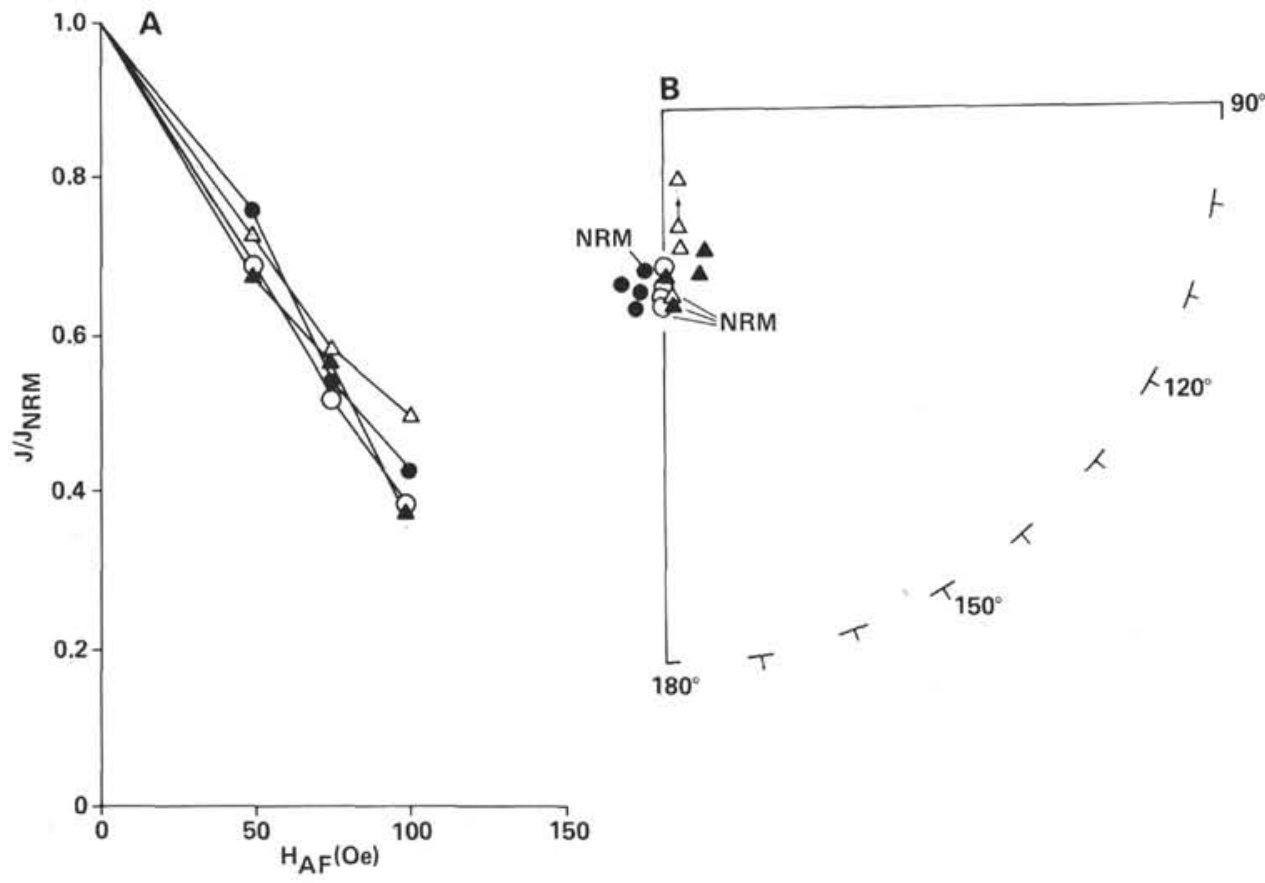

Figure 3. Demagnetization curve of normalized intensity versus peak alternating field for four samples from Core 29, Section 1(A) and equal area Stereonet plot of corresponding directional changes on AF demagnetization for the same samples (B).
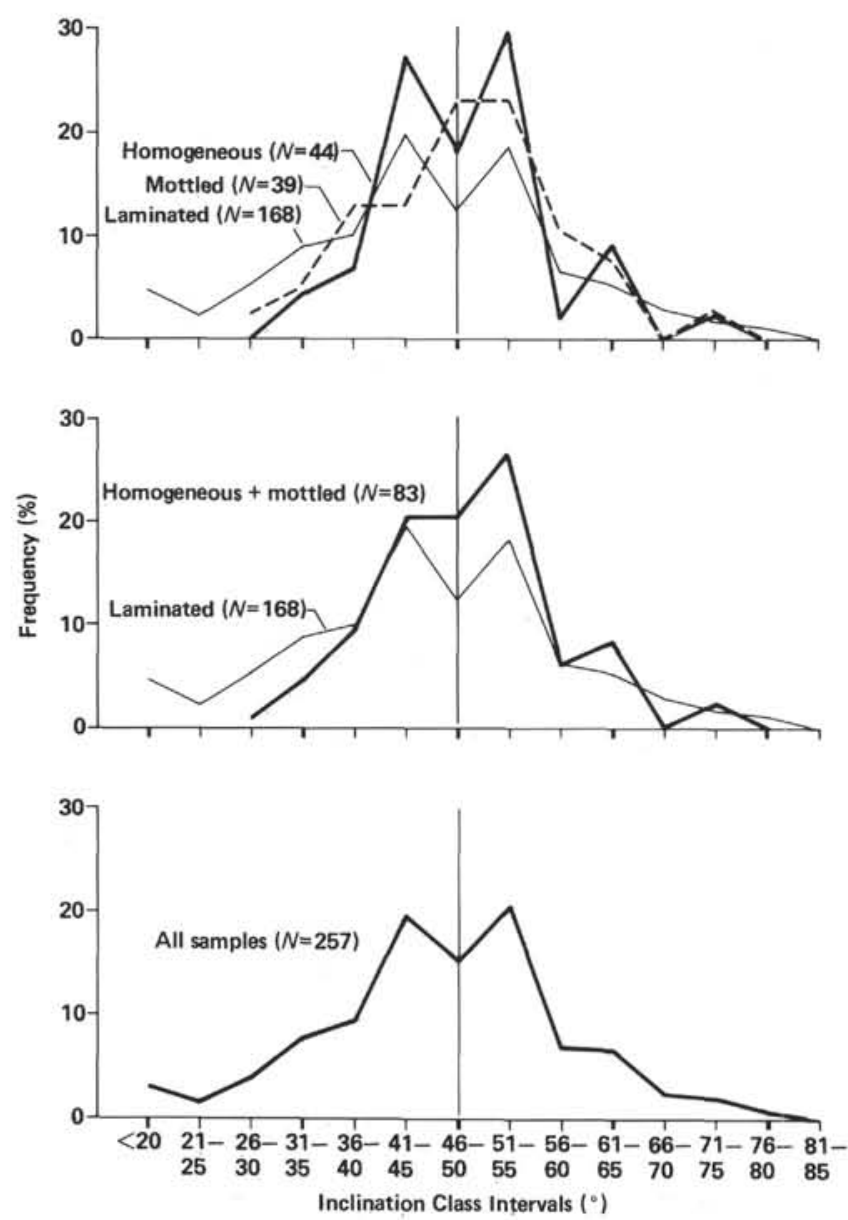

Figure 4. Frequency distributions of inclination at $5^{\circ}$-class intervals for laminated, homogeneous, and mottled sediment lithologies.
Table 1. Summary of mean NRM inclinations and wet-weight normalized intensities for the different lithologies of Hole 480 .

\begin{tabular}{lrrrrrrr}
\hline & \multicolumn{3}{c}{ Inclination $\left(^{\circ}\right)$} & \multicolumn{3}{c}{$\begin{array}{c}\text { Intensity } \\
\left(\times 10^{-7} \text { emu/gm }\right)\end{array}$} \\
Lithology & Mean & \multicolumn{1}{c}{$s$} & $\begin{array}{c}\text { No. } \\
\text { Samples }\end{array}$ & Mean & $s$ & $\begin{array}{r}\text { No. } \\
\text { Samples }\end{array}$ \\
\hline Laminated & 44.6 & 16.1 & 168 & 2.19 & 1.36 & 175 \\
Homogeneous & 49.5 & 8.4 & 44 & 3.88 & 1.34 & 44 \\
Mottled & 49.2 & 9.3 & 39 & 3.88 & 1.13 & 39 \\
Other & 54.9 & 13.1 & 6 & 4.37 & 0.60 & 6 \\
All samples & 46.4 & 14.3 & 257 & 2.77 & 1.54 & 264 \\
\hline
\end{tabular}

Table 2. Summary of mean NRM inclinations and wet-weight normalized intensities above and below 75 meters for the different lithologies of Hole 480 .

\begin{tabular}{|c|c|c|c|c|c|c|c|c|}
\hline \multirow[b]{2}{*}{ Lithology } & \multirow[b]{2}{*}{$\begin{array}{l}\text { Depth } \\
\text { Interval } \\
(\mathrm{m})\end{array}$} & \multicolumn{3}{|c|}{ Inclination $\left({ }^{\circ}\right)$} & \multicolumn{3}{|c|}{$\begin{array}{c}\text { Intensity } \\
\left(\times 10^{-7} \mathrm{emu} / \mathrm{gm}\right)\end{array}$} & \multirow[b]{2}{*}{$\frac{J_{<75 n}}{J_{>75 n}}$} \\
\hline & & Mean & s & $\begin{array}{c}\text { No. } \\
\text { Samples }\end{array}$ & Mean & $s$ & $\begin{array}{l}\text { No. } \\
\text { Samples }\end{array}$ & \\
\hline \multirow[t]{2}{*}{ Laminated } & $<75$ & 44.7 & 11.8 & 54 & 2.86 & 1.16 & 58 & 1.5 \\
\hline & $>75$ & 44.6 & 17.8 & 114 & 1.85 & 1.33 & 117 & - \\
\hline Homogeneous & $<75$ & 49.1 & 8.5 & 62 & 4.16 & 1.17 & 62 & 1.4 \\
\hline + Mottled & $>75$ & 50.2 & 9.6 & 21 & 3.06 & 1.06 & 21 & - \\
\hline \multirow[t]{2}{*}{ Other } & $<75$ & 59.3 & 8.6 & 5 & 4.19 & 0.47 & 5 & - \\
\hline & $>75$ & 33.3 & - & 1 & 5.25 & - & 1 & - \\
\hline \multirow[t]{2}{*}{ All samples } & $<75$ & 47.6 & 10.6 & 121 & 3.56 & 1.31 & 125 & 1.7 \\
\hline & $>75$ & 45.4 & 16.9 & 136 & 2.06 & 1.38 & 139 & - \\
\hline
\end{tabular}

clination with depth. This effect has been observed in drying experiments of wet lake sediments (Stober and Thompson, 1969; Levi and Banerjee, in preparation); however, verifying this hypothesis must await planned laboratory redeposition and anhysteretic and isothermal remanence experiments. 

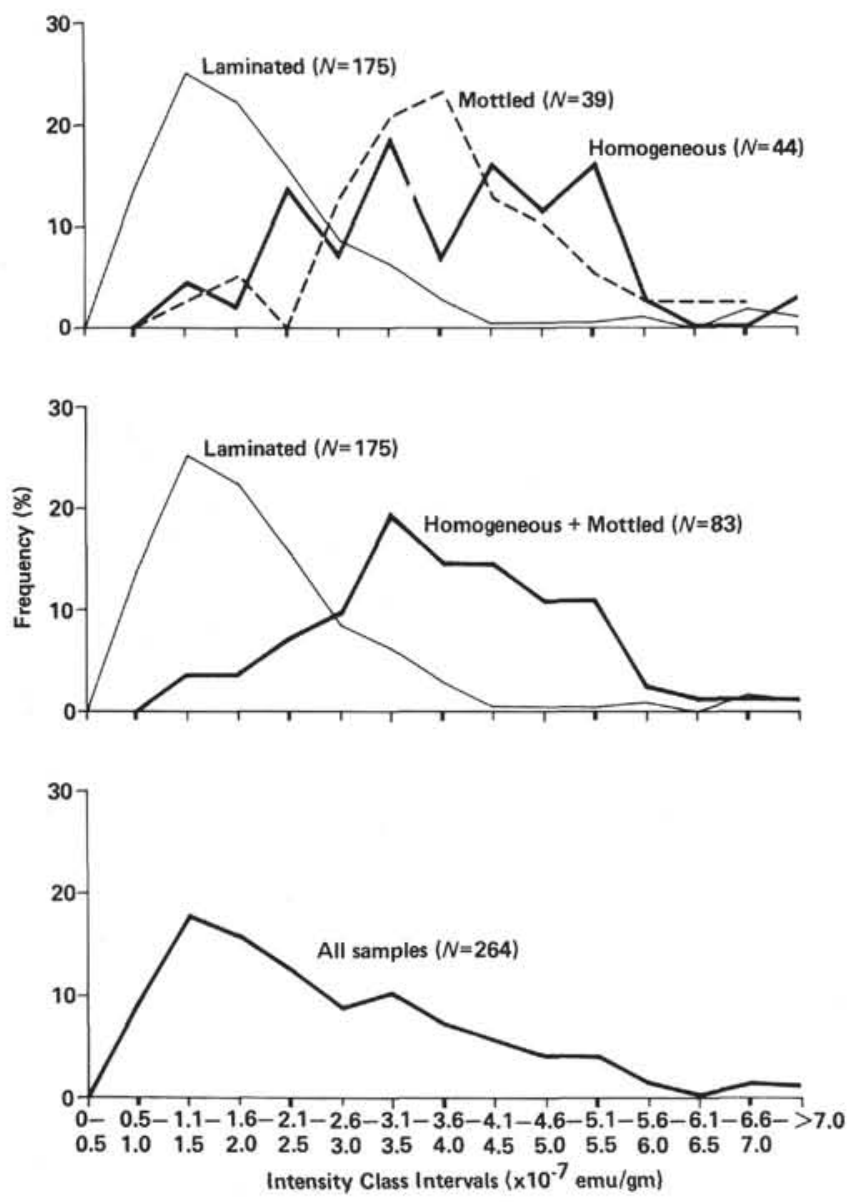

Figure 5. Frequency distributions of intensity at $0.5 \times 10^{-7} \mathrm{emu} / \mathrm{gm}$ (wet weight) class intervals for laminated, homogeneous, and mottled sediments.

\section{CONCLUSIONS}

1. The NRM inclinations of the 152 meters of sediments from Hole 480 are normally magnetized. This result is consistent with micropaleontological and varvecount chronologies, suggesting that the cored section was deposited entirely within the Brunhes Epoch. We observed no geomagnetic reversals throughout the sampled section.

2. The mean NRM inclination for the entire section is about $46^{\circ}$, which is identical to the expected geocentric axial dipole inclination.
3. We observed no inclination error or shallowing of the inclination with depth.

4. The mean inclination for the 75-Oe AF demagnetized samples was very similar to their mean NRM inclination, indicating that only minor secondary magnetization was present.

5. There was no significant difference in the mean NRM inclinations of the laminated, homogeneous, and mottled sediments, suggesting that remanence was acquired below the zone of bioturbation.

6. Intensity differences between mottled/homogeneous and laminated sediments are probably caused by biogenic dilution of the magnetic fraction in the laminated sediments.

7. The mean NRM intensities of sediments above 75 meters are significantly greater than the intensities below this depth, independent of lithology. The decrease in intensity with depth is probably related to increased compaction that may have caused randomization of the remanence-carrying grains without affecting the remanence directions.

\section{ACKNOWLEDGMENTS}

We thank Hans Schrader for stimulating our interest in this project, Kerry Kelts and David Moore for supporting our shore-based participation, Kenneth Verosub and Dennis Kent for very prompt and helpful reviews, David Murray for help in sampling, and Dennis Schultz for invaluable laboratory assistance. This research is supported by NSF grant OCE 7926440 .

\section{REFERENCES}

Creer, K. M., 1974. Geomagnetic variations for the interval 700025000 yr. B.P. as recorded in a core of sediment from station 1474 of the Black Sea cruise of "Atlantis II." Earth Planet. Sci. Lett., 23:34-42.

Curray, J. R., and Moore, D. G., 1979. Initial Core Descriptions: Deep Sea Drilling Project Leg 64, Gulf of California.

Denham, C. R., and Cox, A., 1971. Evidence that the Laschamp polarity event did not occur 13300-30400 years ago. Earth Planet. Sci. Lett., 13:181-190.

Schrader, H., Kelts, K., Curray, J., et al., 1980. Laminated diatomaceous sediments from the Guaymas Basin slope (Central Gulf of California): 250,000-year climatic record. Science, 207:12071208.

Stober, J. C., and Thompson, R., 1979. Magnetic remanence acquisition in Finnish lake sediments. Geophys. J. Royal Astron. Soc., $57: 720-740$.

Verosub, K. L., 1977. The absence of the Mono lake geomagnetic excursion from the paleomagnetic record of Clear lake, California. Earth Planet. Sci. Lett., 36:219-230. 